\title{
AN ORTHOGONALITY PROPERTY FOR REAL SYMMETRIC MATRIX POLYNOMIALS WITH APPLICATION TO THE INVERSE PROBLEM
}

\author{
Peter Lancaster, Uwe Prells and Ion Zaballa
}

Abstract. An orthogonality property common to a broad class of real symmetric matrix polynomials is developed generalizing earlier results concerning polynomials of second degree. This property is obtained with the help of canonical forms expressed in terms of a triple of real matrices (even though there may be complex spectrum) and it is used in the solution of an inverse spectral problem. The distribution of eigenvalues on the real line is discussed and earlier results for quadratic polynomials are generalized, in which the inertias of coefficient matrices are expressed in terms of the canonical forms.

Mathematics subject classification (2010): 47A56, 15A22, 39A99.

Keywords and phrases: Matrix polynomials, orthogonality, inverse problems.

\section{REFERENCES}

[1] M. Al-Ammari, F. Tisseur, Structured inverse quadratic eigenvalue problems, technical report, Manchester Institute for Mathematical Sciences, The University of Manchester, UK, 2012, MIMS Eprint 2011.37, 2011.

[2] I. Gohberg, P. LANCASTER, AND L. Rodman, Spectral analysis of matrix polynomials -1. Canonical forms and divisors, Linear Algebra and its Applications 20 (1978), 1-44.

[3] I. Gohberg, P. LAnCASTER, AND L. Rodman, Representations and divisibility of operator polynomials. Canadian J.Math. 30 (1978), 1045-1069.

[4] I. GohberG, P. LANCASTER, AND L. Rodman, Spectral analysis of selfadjoint matrix polynomials, Research paper 419, 1979, Dept. Mathematics and Statistics, University of Calgary, Canada.

[5] I. Gohberg, P. Lancaster, And L. Rodman, Spectral analysis of selfadjoint matrix polynomials, Annals of Math. 112 (1980), 33-71.

[6] I. Gohberg, P. LanCaster, And L. Rodman, Matrix Polynomials, Academic Press, New York, 1982, and SIAM, Philadelphia, 2009.

[7] I. Gohberg, P. Lancaster, And L. Rodman, Indefinite Linear Algebra and Applications, Birkhäuser, Basel, 2005.

[8] R. A. Horn, Ch. R. Johnson, Topics in Matrix analysis, Cambridge University Press, New York, 1991.

[9] P. LANCASTER, Inverse spectral problems for semisimple damped vibrating systems, Siam J. Matrix Anal. Appl. 29 (2007), 279-301.

[10] P. LANCASTER, AND U. PRells, Inverse problems for damped vibrating systems, J. of Sound and Vibration 283 (2005), 891-914.

[11] P. Lancaster, M. Tismenetsky, The Theory of Matrices, Academic Press, New York, 1985.

[12] P. LANCASTER, AND I. ZABALLA, A review of canonical forms for selfadjoint matrix polynomials, Operator Theory: Advances and Applications 218 (2012), 425-443.

[13] C. Mehl, L. Rodman, Symmetric matrices with respect to sesquilinear forms, Linear Algebra Appl. 349 (2002), 55-75.

[14] B. Parlett, The Symmetric Eigenvalue Problem, Prentice Hall, Englewood Cliffs, N.J., 1980.

[15] U. PRELls, Eine Regularisierungsmethode für die lineare Fehlerlokalisierung von Modellen elasomechanischer Systeme, Doktor-Ingenieur Dissertation, Hannover, 1995. 